\title{
Journal of Geriatric Psychiatry and Neurology
}

\section{Premorbid IQ Influence on Screening Tests' Scores in Healthy Patients and Patients With Cognitive Impairment \\ Lara Alves, Mário R. Simões, Cristina Martins, Sandra Freitas and Isabel Santana \\ J Geriatr Psychiatry Neurol published online 12 April 2013 \\ DOI: $10.1177 / 0891988713484194$}

The online version of this article can be found at:

http://jgp.sagepub.com/content/early/2013/04/15/0891988713484194

\author{
Published by: \\ @SAGE \\ http://www.sagepublications.com
}

Additional services and information for Journal of Geriatric Psychiatry and Neurology can be found at:

Email Alerts: http://jgp.sagepub.com/cgi/alerts

Subscriptions: http://jgp.sagepub.com/subscriptions

Reprints: http://www.sagepub.com/journalsReprints.nav

Permissions: http://www.sagepub.com/journalsPermissions.nav

>> OnlineFirst Version of Record - Apr 15, 2013

OnlineFirst Version of Record - Apr 12, 2013

What is This? 


\title{
Premorbid IQ Influence on Screening Tests' Scores in Healthy Patients and Patients With Cognitive Impairment
}

Journal of Geriatric Psychiatry and Neurology

$00(0) \mathrm{I}-10$

(C) The Author(s) 2013

Reprints and permission: sagepub.com/journalsPermissions.nav DOI: $10.1177 / 0891988713484194$ jgpn.sagepub.com

(S)AGE

\author{
Lara Alves, $\mathbf{P h D}{ }^{1}$, Mário R. Simões, $\mathbf{P h D}^{2}$, Cristina Martins, $\mathbf{P h D}^{3}$, \\ Sandra Freitas, $\mathbf{P h D}^{\prime}$, and Isabel Santana, $\mathrm{PhD}^{4}$
}

\begin{abstract}
Cognitive screening tests are well-established tools for detecting cognitive impairment, but concerns regarding the influence of premorbid intelligence on patient's performance and cognitive status classification remain. Risk of inaccurate assessment especially affects the elders with high or low premorbid intelligence (who are more likely to be misclassified). The present study examines the influence of premorbid intelligence assessed by the TeLPI (an irregular words reading test) on 2 cognitive screening tests, the Mini-Mental State Examination (MMSE) and the Montreal Cognitive Assessment (MoCA), in healthy participants and patients with cognitive impairments (mild cognitive impairment and Alzheimer disease). Results show that premorbid IQ influences the MMSE and the MoCA scores in both the groups, predicting variance from $8.4 \%$ to $33.2 \%$, according to test and group analyzed. Hence, we propose that whenever the MMSE or the MoCA is used, premorbid IQ evaluation should also be considered to ensure correct interpretation and classification.
\end{abstract}

\section{Keywords}

premorbid IQ, TeLPI, MMSE, MoCA, mild cognitive impairment, Alzheimer disease

\section{Introduction}

Several studies have demonstrated that performance in screening tests is influenced by sociodemographic variables such as age and educational level. ${ }^{1-3}$ The influence of health variables such as depression or family history of dementia on performance has also been reported in the literature. ${ }^{2}$ However, few studies have examined the influence of premorbid ability (or premorbid IQ) on screening tests. ${ }^{4-6}$ Premorbid IQ assessment is considered essential for the clinical diagnosis of dementia and age-related cognitive decline, since baseline test data referring to previous premorbid functioning against which an individual's current performance can be compared are necessary for evaluating the changes in cognition over time. ${ }^{7,8}$

Both the Mini-Mental State Examination (MMSE) ${ }^{9,10}$ and the Montreal Cognitive Assessment (MoCA) ${ }^{11,12}$ are widely used as cognitive screening tests. Several studies have concluded that premorbid IQ, along with age and education, is a major predictor of MMSE scores in healthy adults ${ }^{5,9}$ as well as in dementia across a wide range of severity. ${ }^{6}$ So far, to our knowledge, no study has been conducted to research the influence of premorbid IQ on MoCA scores, although the effect of age and years of education on these scores has been recently examined. ${ }^{1}$ Education has been widely reported as a marker for premorbid IQ. ${ }^{4,13-18}$ Education level has also been used as a substitute for cognitive reserve, ${ }^{17,19}$ and both brain and cognitive reserve models converge in the assumption that individuals with a high cognitive reserve show a delay in the appearance of symptoms and retain a clinical advantage compared to low reserve patients. ${ }^{4}$ In the brain reserve capacity model, ${ }^{20,21}$ clinical or functional impairment will appear only when such reserve is depleted over a critical threshold, varying among patients. In the cognitive reserve model hypothesis, the focus is on the ability to optimize the performance through the differential recruitment of brain networks that may reflect the use of alternative cognitive strategies. ${ }^{19}$ It is hypothesized that a greater pathological load is needed to produce the same severity of dementia in those with increased cognitive reserve and

\footnotetext{
' Faculty of Psychology and Educational Sciences, University of Coimbra, Coimbra, Portugal

${ }^{2}$ Psychological Assessment Lab, CINEICC, Faculty of Psychology and Educational Sciences, University of Coimbra, Coimbra, Portugal

${ }^{3}$ Department of Languages, Literatures and Cultures, Center of General and Applied Linguistics, University of Coimbra, Coimbra, Portugal

${ }^{4}$ Department of Neurology, Coimbra University Hospital and Faculty of Medicine, University of Coimbra, Portugal
}

\section{Corresponding Author:}

Lara Alves, University of Coimbra, Rua do Colégio Novo, Apartado 6153, Coimbra 3001-802, Portugal.

Email: laralves79@gmail.com 
that dementia severity predicts the rate of subsequent decline. ${ }^{22}$ However, the cognitive reserve model also predicts that higher functioning individuals will show a more rapid deterioration over time. In fact, if greater cognitive reserve allows the brain to cope with a greater amount of damage, when this reserve is exhausted, a faster rate of decline is also expected. ${ }^{4,19,22}$ Previous findings on the relationship between education and Alzheimer disease (AD) progression have been controversial, with positive association reports, ${ }^{23,24}$ negative associations, ${ }^{25}$ and neutral. ${ }^{26}$ However, more recent studies on both preclinical and incident $\mathrm{AD}$ cases show a positive association between higher education and faster global, memory, and executive decline. ${ }^{16,17}$ The cognitive reserve model predicts a faster rate of cognitive decline when the reserve is overloaded, but slower progression is expected in very mild cases or normal individuals with higher cognitive reserve. ${ }^{27,28}$

Although this paradigm is yet to be established, a measure of cognitive reserve is thought to be useful, ${ }^{18}$ since elders displaying high premorbid intelligence are more likely to be misclassified as normal, while those with low premorbid intelligence are more likely to be misclassified as demented. ${ }^{5}$ Quantifying relationships between premorbid IQ and cognitive test results should allow for more accurate adjustments of premorbid IQ, when neuropsychological assessment is part of the diagnostic process ${ }^{6}$ and can otherwise contribute to rule out a prior cerebral disease. ${ }^{29}$

The development of the irregular words reading test ${ }^{30}$ for Portuguese speakers and its validation in mild cognitive impairment (MCI) and mild-to-moderate $\mathrm{AD}$ groups ${ }^{31}$ afforded the possibility for the study of this relationship in the Portuguese population.

The TeLPI ${ }^{13}$ is a reading test containing 46 Portuguese words of decreasing familiarity in similar concept to the National Adult Reading Test (NART)-Revised. ${ }^{32}$ Each word presents at least one case of nonbiunivocal and thus irregular grapheme - phoneme correspondence. Since correct pronunciation of words presenting irregular letter-sound pairings cannot be accomplished through the application of grapheme-tophoneme conversion rules and guesswork, it has been argued that performance on irregular words reading tests is most likely to depend on previous knowledge than on current cognitive capacity. ${ }^{32,33}$

The TeLPI scores are correlated with the full-scale intelligence quotient (FSIQ) of the Portuguese version of the Wechsler Adult Intelligence Scale-Third Edition (WAIS-III ${ }^{34}$ ), and the test incorporates demographic variables in regression formulas that explain $63 \%$ of FSIQ variance in accordance with other reading tests that typically report variances such as $55 \%$ $\left(\mathrm{NART}^{33}\right), 61 \%$ (Hopkins adult reading test ${ }^{35}$ ), and $65 \%$ (Test of Premorbid Functioning-UK version [TOPF-UK $\left.{ }^{36}\right]$ ). The TeLPI exhibits very good psychometric properties, since it has an excellent internal consistency and test-retest reliability, ${ }^{13}$ also in line with research on other reading tests. ${ }^{35,37}$

Hence, the aim of this study is to investigate the influence of premorbid IQ on MMSE and MoCA scores using the TeLPI, both in healthy patients and patients with cognitive impairment and eventually to ascertain the indication for an adjustment of MMSE and MoCA scores according to an expected level of performance.

\section{Methods}

\section{Participants}

The total study sample is composed of 208 participants distributed across 3 groups: (1) the mild cognitive impairment (MCI) group with 53 patients, (2) the AD group with 51 patients, and (3) the cognitively healthy group with 104 adults. Patients were recruited at the Dementia Clinic, Neurology Department of the Coimbra University Hospital (Coimbra University Hospital, Coimbra, Portugal). Healthy participants were selected in the community, matching patients in gender, age, educational level, and place of residence. The demographic data of the participants are provided in Table 1.

To implement and confirm the standard clinical criteria, all patients were submitted to a comprehensive neurological and neuropsychological evaluation. The neurological evaluation was performed by a neurologist and included: (1) a detailed history provided by the patient and by a reliable source, (2) a neurological examination, and (3) a psychiatric evaluation. Patients were investigated with routine laboratory examinations/analysis for dementia, structural imaging studies (computed tomography $[\mathrm{CT}]$ and/or magnetic resonance imaging), single-photon emission CT, and apolipoprotein E genotyping mainly to exclude other dementia diseases or relevant medical conditions. The PET and cerebrospinal fluid analysis were carried out more restrictively but always considered in younger patients (below 60 years of age). The neuropsychological assessment was performed by trained neuropsychologists and included a comprehensive neuropsychological assessment battery with the following instruments:

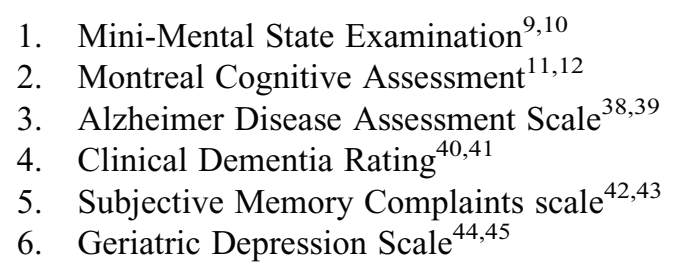

The diagnosis was established by a multidisciplinary team consensus, considering the results of the assessment and based on the international criteria for MCI of the Petersen workgroup $^{46}$ and for probable $\mathrm{AD}{ }^{47,48}$ The $\mathrm{MCI}$ group included patients classified as "amnesic MCI" (single or multidomain $^{49}$ ) and with a complementarity-determining region (CDR) classification of 0.5. On the other hand, the AD group included patients only with mild-to-moderate severity (classified with CDR $\leq 2$ and MMSE $\geq 12$ ). In addition, the patients were excluded from the study if any of the following criteria were met:

1. Birthplace or completion of formal education outside of Portugal. 


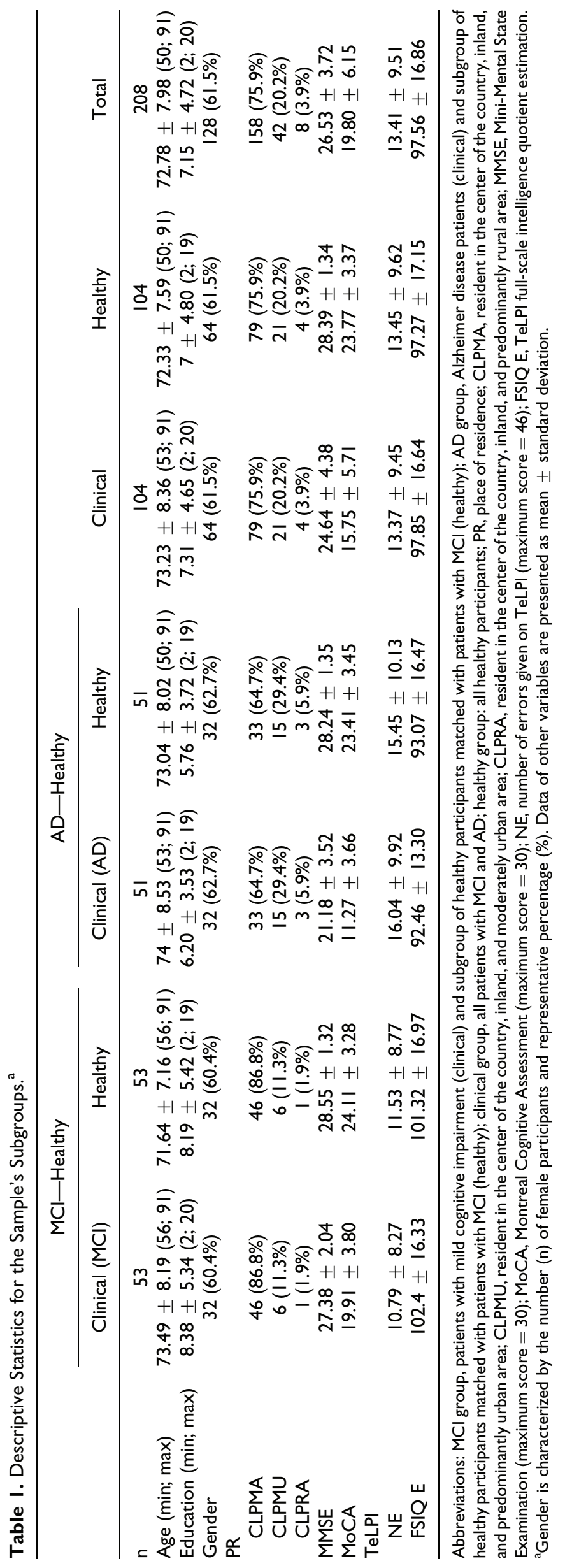


2. Inability to read or understand written Portuguese.

3. Acute/instable somatic disease.

4. Recent psychiatric comorbidities or therapeutic changes (6 months prior to the current neuropsychological evaluation).

5. Significant motor, visual, or auditory deficits that could influence the neuropsychological assessment results.

The healthy group participants were recruited in the community and selected for the study according to age (group), gender, educational level, and area of residence in order to match patients belonging to both the clinical samples. As a result, there was an almost perfect match between MCI or axial diffusion groups and associated healthy participants. Inclusion criteria for healthy participants were

1. Birthplace and completion of formal education in Portugal.

2. Ability to read and understand written Portuguese.

3. Absence or correction of motor, speech, audition, or vision disorder.

4. No past history of head injury with loss of consciousness, major psychiatric, or neurological disorders that could affect cognitive ability as well as of chronic unstable systemic disorders with impact on cognition.

5. No symptoms of cognitive impairment including diminished autonomy in daily activities.

6. No history of alcoholism or substance abuse.

7. Absence of significant depressive complaints and medication with possible impact on cognition (eg, psychotropic or psychoactive drugs).

\section{Procedures}

All participants were recruited between June 2009 and January 2012 and completed the assessment in a single session by a neuropsychologist. Only patients with a complete clinical evaluation, fulfilling the inclusion criteria, presenting a stable clinical condition, and a well-established diagnosis, were considered to be eligible for this study. The healthy condition of the control group participants was also ascertained by an interview performed by a neuropsychologist, using a standard questionnaire that included a complete sociodemographic survey, an inventory of current clinical health status, the past habits, and a medical history. This information was also checked with the general practitioners and/or an informant (usually an individual who lived with the participant or a close relative). All instruments were applied strictly following manual instructions.

The present research complied with the Declaration of Helsinki ethical guidelines for human experimentation and was approved by the Ethics board of Coimbra University Hospital, by the "Fundação para a Ciência e Tecnologia" (Portuguese Foundation for Science and Technology), and by the Faculty of Psychology and Educational Sciences Scientific Committee. All patients gave their informed consent after the aim of the study was explained to them. For the patients with AD who were incapable of providing consent, a legal representative provided it on their behalf.

Statistical analysis was performed with the SPSS (version 19.0; IBM SPSS, Chicago, Illinois). Descriptive statistics and chi-square were used for the sample's characterization, and the 2-sample $t$ test, along with the analysis of covariance (ANCOVA) and regressions (Enter method), allowed for group comparisons and variables influence.

\section{Neuropsychological Testing and Materials}

In the initial clinical interview performed by a neuropsychologist, the demographic and clinical data were collected though a complete sociodemographic questionnaire, an inventory of current and past clinical health status, the habits, and a medical history. The interview was followed by the administration of the following materials (in addition to the previously mentioned instruments included in the standard battery that was used for inclusion criteria only): MMSE, MoCA, and TeLPI, in this fixed order for all patients.

Both the MMSE and the MoCA are in paper-and-pencil format and are scored out of a possible 30 points, with higher scores indicating better cognitive performance. The MMSE is a screening test grouped into 7 categories: (1) orientation, (2) registration, (3) attention and concentration, (4) recall, (5) language, (6) repetition, and (7) visual construction. The MoCA screens milder forms of cognitive impairment through the assessment of 6 cognitive domains: (1) executive functions, (2) visuospatial abilities, (3) short-term memory, (4) language, (5) attention, concentration, and working memory, and (6) temporal and spatial orientation. The MoCA is a 1-page test with an application time of approximately 10 to 15 minutes and includes a manual where explicit instructions concerning its administration and scoring system are provided. The greater diagnostic accuracy and discriminant validity of the MoCA as a global cognitive assessment instrument in comparison with $\mathrm{MMSE}^{50}$ justifies its use in the present study.

The TeLPI is an instrument specially developed for the Portuguese population that uses valid regression formulas for estimating premorbid intelligence, which include performance scores (number of errors in irregular words reading) with sociodemographic variables (years of education). ${ }^{13}$ The TeLPI is easy to apply, short (3-5 minutes to administer), well tolerated, exhibits excellent concurrent validity, and is, overall, valid for premorbid intelligence estimation in a normal population, filling an important gap in the neuropsychological evaluation of adult Portuguese speakers aged 25 to $86 .{ }^{13}$ The TeLPI is composed of a card with 46 printed irregular words, a registering form with the indication of different possibilities for correct pronunciation (according to linguistic variation in Portugal), the regression formulas used for the WAIS-III FSIQ, Verbal Intelligence Quotient and Performance Intelligence Quotient, a manual with explicit instructions concerning its administration and scoring system, and a CD recording admissible pronunciations for European Portuguese, as to simplify scoring. Recording of patients' sessions is recommended, allowing for 
Table 2. Correlations Between MMSE/MoCA and Age, Education and TeLPI's Premorbid IQ Estimation. ${ }^{\mathrm{a}}$

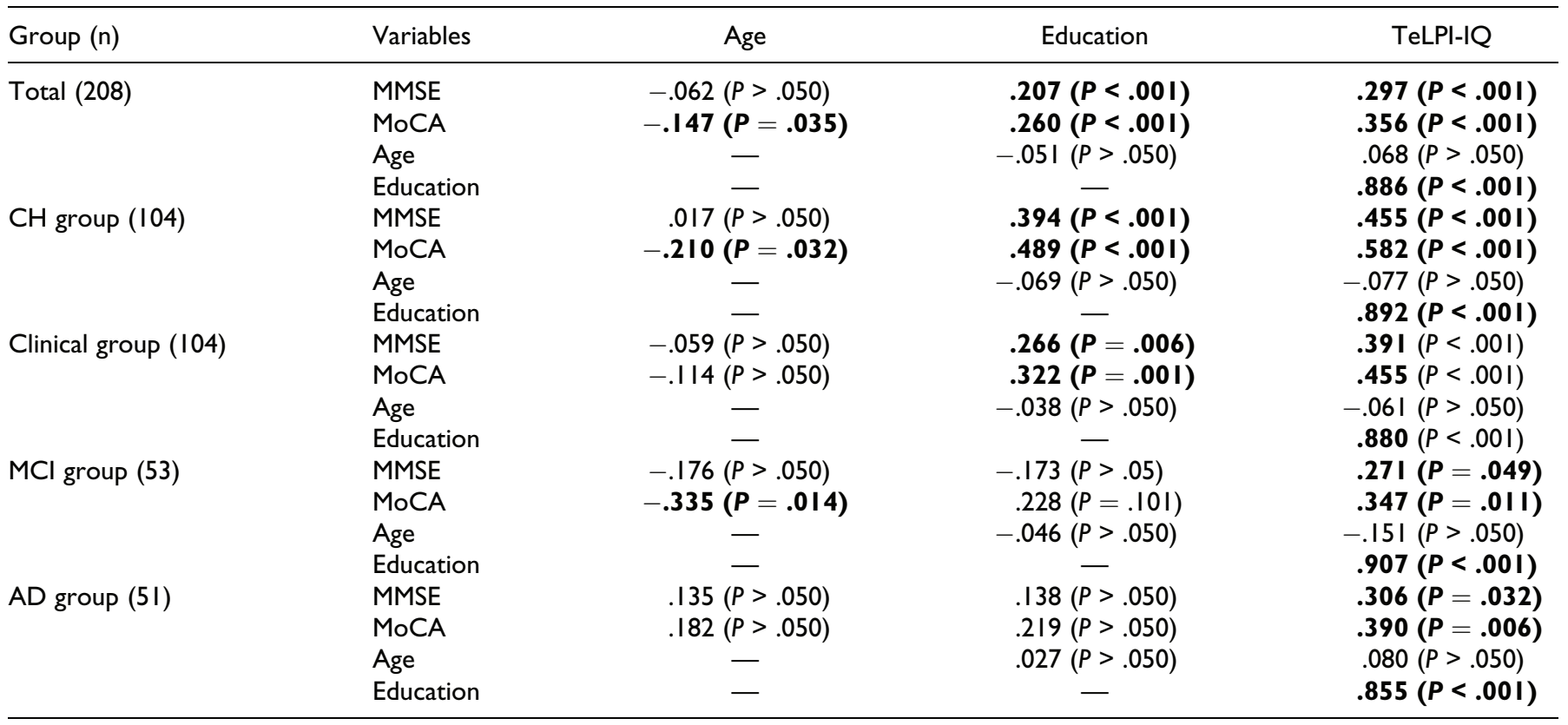

Abbreviations: $\mathrm{AD}$, Alzheimer disease; $\mathrm{CH}$ group, cognitively healthy group; clinical group, all patients with $\mathrm{MCl}$ and $\mathrm{AD}$; MMSE, Mini-Mental State Examination; MoCA, Montreal Cognitive Assessment; $\mathrm{MCl}$, mild cognitive impairment.

${ }^{a}$ Education is evaluated in years successfully completed at school.

Note: Significant correlation (2-tailed) are marked in bold.

future consideration in the case of doubts regarding scoring (procedure that was followed in the present study).

\section{Results}

Characteristics of the groups are provided in Table 1, considering sample size, age, educational level, gender, residence, MMSE scores, MoCA scores, and 2 TeLPI-related data (number of errors and FSIQ estimation).

As mentioned earlier, the control participants were selected as to match patients in the clinical groups and are therefore considered demographically equivalent. Consequently, no statistically significant differences were found between control and clinical groups on age $\left(t_{(206)}=-.81, P>.05\right)$, years of education $\left(t_{(206)}=-.46, P>.05\right)$, gender $\left(\kappa^{2}{ }_{(1)}=.000, P=1.0\right)$, and area of residence $\left(\kappa^{2}{ }_{(2)}=.000, P=1.0\right)$. When analyzing differences between the groups (MCI/control and $\mathrm{AD} /$ control) in more detail, as for age $\left(t_{(102)}=-.92, P>.05\right)$, gender $\left(\kappa^{2}{ }_{(1)}=\right.$ $.000, P=1.0)$, and area of residence $\left(\kappa^{2}{ }_{(2)}=.000, P=1.0\right)$, the nonsignificance relation continues to hold, but since educational levels $(1-4 / 5-9 / 10-12 />12)$ were used in defining the sample, the difference between the groups regarding the variable years of education was found to be significantly different $\left(t_{(102)}=2.44, P<.05\right)$. The MMSE scores $\left(t_{(102)}=11.52, P<\right.$ $.001)$ and MoCA scores $\left(t_{(102)}=11.66, P<.001\right)$ were also found to be significantly different. Using an ANCOVA for the years of education variable control, no statistically significant differences were observed in number of errors on the TeLPI between controls, MCI, and probable patients with $\mathrm{AD}$ $\left(F_{(2,207)}=1.42, P>.05, \eta_{\mathrm{p}}{ }^{2}=.014\right)$, suggesting that the diagnosis has a very slight effect in TeLPI results. ${ }^{51}$ In contrast, the difference between the scores in the MMSE $\left(F_{(2,207)}=\right.$ 186.4, $\left.P<.001, \eta_{\mathrm{p}}{ }^{2}=.649\right)$ and in the MoCA $\left(F_{(2,207)}=\right.$ 223.6, $\left.P<.001, \eta_{\mathrm{p}}{ }^{2}=.689\right)$ was found to be statistically significant between control, MCI, and AD groups, supporting the sensitivity of these instruments in detecting cognitive deterioration. The results on the MMSE and the MoCA represent the deterioration along the spectrum of cognitive impairment, with patients with $\mathrm{AD}$ obtaining lower scores than patients with MCI.

In contrast with the results obtained by screening instruments for cognitive deterioration, no statistically significant differences were found between the TeLPI scores $\left(t_{(206)}=\right.$ $.06, P>.05)$ and the FSIQ estimation $\left(t_{(206)}=-.244, P>\right.$ $.05)$, confirming that irregular words reading performance is equivalent between control and clinical groups.

Correlations between the variables are presented in Table 2 . The TeLPI-IQ was found to have a significant correlation with MMSE and MoCA in all the study groups. The cognitively healthy group displayed higher correlations than the clinical group between the TeLPI and the MMSE and the MoCA. It should be further noted that these correlations were consistently higher between the TeLPI-IQ and the MoCA in all studied groups. Age was not found to significantly correlate with the TeLPI-IQ in any of the groups studied. On the other hand, as expected, the education variable was found to highly correlate with the TeLPI-IQ in all the groups.

Since previous analyses have shown that TeLPI results are reliable across healthy and clinical groups and that no significant differences were found between them, regression equations 
Table 3. TeLPI's-IQ Explained Variance of the Different Study Groups. ${ }^{a}$

\begin{tabular}{|c|c|c|c|c|c|c|c|c|c|c|}
\hline & \multicolumn{10}{|c|}{ Group (n) } \\
\hline $\begin{array}{l}\text { TeLPI-IQ } \\
\quad \text { adjusted } R^{2}\end{array}$ & .084 & .123 & .200 & .332 & .154 & .199 & .094 & .134 & .055 & .103 \\
\hline $\mathrm{B}(\mathrm{Cl})$ & $\begin{array}{c}.066 \\
(.037-.095)\end{array}$ & $\begin{array}{c}.130 \\
(.083-.177)\end{array}$ & $\begin{array}{c}.036 \\
(.022-.049)\end{array}$ & $\begin{array}{c}.114 \\
(.083-.146)\end{array}$ & $\begin{array}{c}.103 \\
(.055-.150)\end{array}$ & $\begin{array}{c}.156 \\
(.096-.216)\end{array}$ & $\begin{array}{c}.069 \\
(.006-.131)\end{array}$ & $\begin{array}{c}.090 \\
(.028-.153)\end{array}$ & $\begin{array}{c}.034 \\
(.000-.068)\end{array}$ & $\begin{array}{c}.081 \\
(.020-.143)\end{array}$ \\
\hline
\end{tabular}

Abbreviations: AD, Alzheimer disease; $\mathrm{CH}$ group, cognitively healthy group; clinical group, all patients with MCI and AD; MMSE, Mini-Mental State Examination; MoCA, Montreal Cognitive Assessment; B, B coefficient; $\mathrm{Cl}$, confidence interval; $\mathrm{MCl}$, mild cognitive impairment.

${ }^{\mathrm{a}} 95 \% \mathrm{Cl}$ is considered for $\mathrm{B}$.

Table 4. Correspondence Between IQ Points and Each MMSE or MoCA Point Gained in the Sample.

\begin{tabular}{lccccc}
\hline & \multicolumn{4}{c}{ Group (n) } \\
\cline { 2 - 6 } & Total (208) & CH Group (104) & Clinical Group (104) & MCI Group (53) & AD Group (5I) \\
\hline MMSE & 15 & 29 & 10 & 29 & 14 \\
MoCA & 8 & 9 & 7 & 12 & 11 \\
\hline
\end{tabular}

Abbreviations: AD, Alzheimer disease; $\mathrm{CH}$ group, cognitively healthy group; clinical group, all patients with $\mathrm{MCl}$ and $\mathrm{AD}$; MMSE, Mini-Mental State Examination; MoCA, Montreal Cognitive Assessment; $\mathrm{MCl}$, mild cognitive impairment.

were computed for all of the 208 patients included in the study. For both the MMSE and the MoCA, the regression equations revealed significant models (MMSE: $\beta=.297, t_{(206)}=$ 4.470, $P<.001$; MoCA: $\left.\beta=.356, t_{(206)}=5.470, P<.001\right)$, and the TeLPI-IQ yielded a $8.4 \%$ prediction on the MMSE variance (adjusted $\left.R^{2}=.084, F_{(1,207)}=19.99, P<.001\right)$ and a $12.3 \%$ prediction on the MoCA variance (adjusted $R^{2}=.084, F_{(1}$, 207) $=19.99, P<.001)$. Furthermore, for the MMSE, we observed a possible variation from .037 to .095 per IQ point (B $=.066,95 \%$ confidence intervals, $P<.001$ ), and for the MoCA, we observed a variation from .083 to .177 per IQ point $(\mathrm{B}=.130,95 \%$ confidence intervals, $P<.001)$.

In a second step analysis, patients were stratified into 2 separate groups (patients and cognitively healthy groups) and linear regressions were also calculated. As presented in Table 3, for the cognitively healthy group, the TeLPI-IQ regression model was found significant for the MMSE $(\beta=.455$, $\left.t_{(102)}=5.164, P<.001\right)$, explaining $20 \%$ of its score variance (adjusted $R^{2}=.200, F_{(1,103)}=26.670, P<.001$ ), ranging from .022 to .049 per IQ point $(\mathrm{B}=.036,95 \%$ confidence intervals, $P<.001)$. Regression equations for the MoCA were also significant in the cognitively healthy group $\left(\beta=.582, t_{(102)}=7.219\right.$, $P<.001$ ), explaining $33.2 \%$ of the score variance (adjusted $R^{2}$ $\left.=.332, F_{(1,103)}=52.11, P<.001\right)$, ranging from .083 to .146 per IQ point $(\mathrm{B}=.114,95 \%$ confidence intervals, $P<.001)$. In the clinical group, this tendency was also observed, yielding significant linear regression models for both the MMSE $(\beta=$ $\left..391, t_{(102)}=4.293, P<.001\right)$ and the MoCA $(\beta=.455$, $\left.t_{(102)}=5.158, P<.001\right)$. The TeLPI-IQ explains $14.5 \%$ of the MMSE score variance (adjusted $R^{2}=.145, F_{(1,103)}=18.430$, $P<.001)$, ranging from .055 to .150 per IQ point $(\mathrm{B}=.036$, $95 \%$ confidence intervals, $P<.001$ ) and $19.9 \%$ of the MoCA score variance (adjusted $R^{2}=.199, F_{(1,103)}=26.605, P<$ $.001)$, in a range from .096 to .216 per IQ point $(\mathrm{B}=.156$, $95 \%$ confidence intervals, $P<.001)$.

In a third analysis, the clinical group was divided according to $\mathrm{MCI}$ or $\mathrm{AD}$ diagnoses, and linear regressions were also calculated. Table 3 presents the regression formula results. The MCI group presented a significant TeLPI-IQ regression model for the MMSE $\left(\beta=.271, t_{(51)}=2.014, P=.049\right)$, explaining $5.5 \%$ of its score variance (adjusted $R^{2}=.055, F_{(1,52)}=4.055$, $P=.049)$, ranging from .000 to .068 per IQ point $(\mathrm{B}=.034$, $95 \%$ confidence intervals, $P=.049)$. Regression equations for the MoCA were also significant in this group $\left(\beta=.347, t_{(51)}=\right.$ $2.645, P=.011)$, explaining $10.32 \%$ of the score variance (adjusted $\left.R^{2}=.103, F_{(1,52)}=6.998, P=.011\right)$, ranging from .020 to .143 per IQ point $(\mathrm{B}=.081,95 \%$ confidence intervals, $P<.001)$. In the AD group, this tendency was also observed, yielding significant linear regression models for both the MMSE $\left(\beta=.306, t_{(49)}=2.205, P=.032\right)$ and the $\operatorname{MoCA}\left(\beta=.390, t_{(49)}\right.$ $=2.900, P=.006)$. The TeLPI-IQ explains $9.4 \%$ of the score variance of the MMSE (adjusted $R^{2}=.094, F_{(1,50)}=4.862$, $P=.032)$, ranging from .006 to .131 per IQ point $(\mathrm{B}=.039$, $95 \%$ confidence intervals, $P=.032$ ) and $13.4 \%$ of the score variance of the MoCA (adjusted $R^{2}=.134, F_{(1,50)}=8.410, P=$ $.006)$, in a range from .028 to .153 per IQ point $(\mathrm{B}=.090$, $95 \%$ confidence intervals, $P=.006$ ).

Table 4 is also presented with the correspondence between IQ points and each MMSE or MoCA point gained in the sample.

\section{Discussion}

The MMSE and MoCA scores were significantly lower in patients (MCI and AD groups) when compared to healthy 
elders. In addition, differences observed between the clinical groups were also anticipated and considered representative of the decline along the spectrum of cognitive impairment, with patients with $\mathrm{AD}$ obtaining lower scores than patients with MCI. In contrast, the TeLPI scores were not statistically different between these groups when the variable years of education was controlled. These results confirm that the capacity for reading irregular words is preserved in the prodromal and in the initial stages of dementia, as reported in previous studies with irregular words reading tests. ${ }^{31,52-56}$

According to our results, TeLPI-IQ correlated significantly with both MMSE and MoCA scores as well as with the years of education variable in all the studied groups. Note that TeLPI-IQ correlations with years of education are similar in all the studied samples. The relationships between premorbid IQ, cognitive screening tests, and education in clinical samples have been previously explored with equivalent results. For example, the $\mathrm{WTAR}^{37}$ exhibits a correlation of .34 between the premorbid functioning and the MMSE in patients with AD that can be considered similar, although smaller than those found in our study for both the MMSE $(r[104]=.391, P<.001)$ and the MoCA $(r[104]=.455, P<.001)$.

Previous studies have also reported the strong and positive relation of education and premorbid IQ on cognitive functioning as measured by the MMSE. ${ }^{4,6,14-17}$ For example, the fNART ${ }^{53}$ another instrument of premorbid intelligence estimation, was also highly related to education level in healthy participants $(r[388]=.57, P<.001)$.

Age was also found to be significantly correlated with performance on the MMSE and the MoCA in previous studies. ${ }^{6,50}$ However, in the present study, this was not confirmed for the MMSE in all the study groups and, in what regard to the MoCA, there was a significant, yet weak correlation (a higher correlation exists in MCI group). The absence of a strong correlation between age and the screening tests' scores in our sample can be more substantially due to the smaller size and limited age range of the sample studied $(\mathrm{M}=72.78$, standard deviation =7.98; min: 50, $\max : 91$ ), compared to the other community studies that were conducted with larger samples and participants distributed along a wide age range. The same tendency is observed in the absence of significant correlations between age and TeLPI-IQ scores. Nevertheless, results similar to our own findings have also been reported, ${ }^{15}$ sustaining that, if intelligence is associated with health in old age, its effects are weakened by the age of 70, thus explaining the lack of correlations between premorbid IQ and age. In fact, age was also not significant in the models derived from the TeLPI final version validation sample, ${ }^{13}$ in line with other premorbid intelligent instruments such as the WTAR, ${ }^{37}$ the TOPF-UK, ${ }^{36}$ and the NART-SWE ${ }^{54}$ that reported no correlation between age and premorbid intelligence when computing the regression formulas.

Although all correlations between the TeLPI-IQ and the screening tests are significant, they are consistently higher with the MoCA. This fact is probably due to MMSE ceiling effects, and also because the MoCA assesses not only more cognitive domains than the MMSE does but also those of greater complexity, such as executive functions, visuospatial abilities, language, attention, concentration, and working memory. ${ }^{11,12,57}$

Since the capacity for reading irregular words was found to be preserved in the prodromal and in the initial stages of dementia, we first opted to consider our sample as a whole. Our related data are in line with other studies, confirming that premorbid IQ influences both MMSE and MoCA scores. ${ }^{6}$ The TeLPI-IQ explains $8.4 \%$ of the MMSE variance and $12.3 \%$ of the MoCA variance. As a consequence, when considering the sample as a whole (see Table 4), 1 MMSE point is gained for every added 15 TeLPI-IQ points, and 1 MoCA point is gained for every added 8 TeLPI-IQ points (other available data are also presented in Table 4 so that different ponderation values can be used according to the clinical preferences). Several misclassification errors can be elicited if this correction is not considered. For example, a patient with 12 years of education and with a score of 28 on the MMSE (according to Portuguese cutoff scores, $\leq 27$ MMSE score indicates cognitive decline in this range of education) would be classified as nonimpaired. Nevertheless, if a premorbid intelligence IQ measure of, for example, 130 is taken into consideration, 2 points on the MMSE should be pondered, revealing that, in fact, the patient has a real MMSE score of 26 and a possible decline outcome score. In the opposite extreme, if a patient with 9 years of education scores 21 on the MMSE (according to Portuguese cutoff scores, $\leq 22$ MMSE score indicates cognitive decline in this range of education), the classification of impairment should be proposed. However, if a premorbid IQ of 70 is taken into consideration, 2 points should be added on the MMSE score, resulting in a corrected MMSE score of 23, which is considered normal. The amount of TeLPI-IQ explained variance in MMSE and MoCA may also indicate that TeLPI is not a redundant instrument but a complementary one in an assessment battery for cognitive decline.

Although there were no significant differences on the TeLPI-IQ between clinical and healthy samples, we decided to develop a more thorough analysis considering the sample groups separately (healthy group vs clinical group), so that comparisons with other studies could be drawn. It is also important to emphasize that, given the lack of studies in analyzing the influence of premorbid IQ on MoCA scores, no comparative analysis involving this screening test in the healthy or in the impaired sample could be conducted.

Differences can be observed when comparing TeLPI's-IQ explained variance in the cognitively healthy group and the clinical group on both the MMSE and the MoCA and between the 2 screening tests. According to our results, TeLPI-IQ explained a higher percentage of the variance of the MMSE and the MoCA scores in the cognitively healthy group than in the clinical group (Table 3). When considering the results of the MCI and the AD groups independently, it can be noted that TeLPI-IQ explains a higher percentage of the variance of the MoCA scores than that of the MMSE scores, following the tendency of the results presented in the previous analysis of this study when the whole sample was considered. Despite the 
rigorous selection criteria applied in both the groups, other health variables may have potentially influenced the performance of the clinical group and account for the difference between explained variance of TeLPI-IQ in the healthy and clinical sample. This was also found in other studies where parasite variables associated with physical and functional status influenced premorbid IQ estimation in clinical samples, without a comparably relevant impact on the healthy population. ${ }^{15}$ In these studies, the crucial importance of taking into account the adaptive ability of an individual within a particular environment, integrating personal cognitive change with more absolute social requirements was also pointed out. Another plausible explanation for these results would include the ceiling effects of both the MMSE and the MoCA in their relation to previous intelligence level. Note that, for healthy participants, 30 points on the MMSE or on the MoCA are typically easier to achieve than for patients in the clinical group, thus originating less variability of the scores in the healthy group, with possible effects on explained variance.

In other studies, the results of both healthy and clinical groups are similar to our own findings. In a clinical group of patients with mild-to-moderate AD, NART-IQ explained $18 \%$ of the MMSE variance, ${ }^{6}$ whereas in our sample, TeLPIIQ explained $15.4 \%$ of this variance in the clinical group, $9.4 \%$ in the $\mathrm{MCI}$ group, and $5.5 \%$ in the $\mathrm{AD}$ group. Besides, the same study concluded that 1 MMSE point is gained for every added 5 IQ points, ${ }^{6}$ representing an even greater influence of the premorbid IQ on this screening test when compared to our own results (see Table 4). Hence, it is possible for patients with IQs in the superior range to score above cutoff on the MMSE or, by inference, on the MoCA at an early stage of AD. Christensen and Jorm, ${ }^{5}$ studying healthy elders, also concluded that patients with high premorbid intelligence are more likely to be misclassified as normal, while those with low premorbid intelligence are more likely to be misclassified as demented. The need for premorbid IQ consideration in dementia assessment is also expressed in normative cognitive aging studies. ${ }^{6,14,15}$

The main limitation of the present study is the inability to determine with certainty which variables influence the difference of the TeLPI's-IQ explained variance between clinical and healthy groups, despite the rigorous sample selection that, on the other hand, does represent one of its major strengths. Further studies could benefit from a more thorough physical and functional examination of the samples as to ascertain possible parasite variables. Another limitation is the fact that only the amnesic subtype of MCI (single or multidomain) was considered, restricting the generalization of our results to other forms of MCI. On the other hand, the rigorous methodology followed in the present study represents added value: the samples are well validated, both healthy and clinical groups are homogeneous with equivalent sample sizes (which reduces the possible biases of sample sizes in statistical analysis), there is perfect matching between groups regarding sociodemographic characteristics, and instruments were rigorously applied with no interrater variability. The present study is also the first to examine the relationship between premorbid intelligence and
MoCA. The growing use of the MoCA in everyday practice and research (in several clinical groups as $\mathrm{MCI}, \mathrm{AD}$, frontotemporal, and vascular dementia) and its overall superiority in comparison with the MMSE as a global cognitive assessment instrument regarding discriminative validity and diagnostic accuracy ${ }^{50}$ justifies the importance of our findings.

Our main conclusion is that a single MMSE or MoCA score should not be used to classify a patient as impaired, unless interpreted in the light of original IQ. This perspective may have important implications for clinical practice and the early detection of dementia preventing misclassification errors, and the risk of healthy participants being considered impaired or impaired participants being assessed as cognitively normal. Even if premorbid IQ is taken into consideration in dementia evaluation, borderline cases will still be difficult to assess, because depending on their adaptive cognitive processes, patients may move across the dementia threshold, modulated by factors such as intercurrent physical illness, changed environment, and so forth. ${ }^{6,58}$ Therefore, if the MMSE and the $\mathrm{MoCA}$ are to be used as screening tests for cognitive impairment, our data indicate that premorbid IQ scores should also be considered to ensure correct interpretation of results from patients with known or suspected cognitive impairment and for a more rigorous classification and intervention.

\section{Declaration of Conflicting Interests}

The author(s) declared no potential conflicts of interest with respect to the research, authorship, and/or publication of this article.

\section{Funding}

The author(s) disclosed receipt of the following financial support for the research, authorship, and/or publication of this article: This research was supported by the Fundação para a Ciência e Tecnologia (Portuguese Foundation for Science and Technology) though a PhD fellowship (SFRH/BD/37748/2007) and by PIC/IC/83206/2007.

\section{References}

1. Freitas S, Simões MR, Alves L, Santana I. Montreal cognitive assessment: influence of sociodemographic and health variables. Arch Clin Neuropsychol. 2012;27(2):165-175.

2. Moraes C, Pinto JA, Lopes MA, Litvoc J, Bottino CM. Impact of sociodemographic and health variables on mini-mental state examination in a community-based sample of older people. Eur Arch Psychiatry Clin Neurosci. 2010;260(7):535-542.

3. Rossetti HC, Lacritz LH, Cullum CM, Weiner MF. Normative data for the Montreal Cognitive Assessment (MoCA) in a population-based sample. Neurology. 2011;77(13):1272-1275.

4. Bracco L, Piccini C, Baccino M, et al. Pattern and progression on cognitive decline in Alzheimer's disease: role of premorbid intelligence and ApoE genotype. Dement Geriatr Cogn Disord. 2007; 24(6):483-491.

5. Christensen H, Jorm AF. Effect on premorbid intelligence on the Mini-Mental State and IQCODE. Int J Geriatr Psychiatry. 1992; 7(3):159-160. 
6. Star JM, Lonie J. The influence of pre-morbid IQ on mini-mental state examination score at time of dementia presentation. Int J Geriatr Psychiatry. 2007;22(4):382-384.

7. American Psychological Association. Guidelines for the evaluation of dementia and age-related cognitive decline. Am Psychol. 1998;53(12):1298-1303.

8. Budson AE, Solomon PR. New diagnostic criteria for Alzheimer's disease and mild cognitive impairment for the practical neurologist. Pract Neurol. 2012;12(2):88-96.

9. Folstein MF, Folstein SE, McHugh PR. "Mini-Mental State". A practical method for grading the cognitive state of patients for the clinician. J Psychiatr Res. 1975;12(3):189-198.

10. Guerreiro M, Silva AP, Botelho MA. Adaptação à população portuguesa da tradução do "Mini Mental State Examination" (MMSE) [Adaptation to the Portuguese population of the "Mini Mental State Examination" (MMSE)]. Rev Port Neurol. 1994;1(9):9-10.

11. Nasreddine Z, Phillips NA, Bédirian V, et al. The Montreal Cognitive Assessment, MoCA: a brief screening tool for mild cognitive impairment. J Am Geriatr Soc. 2005;53(4):695-699.

12. Simões MR, Freitas S, Santana I, et al. Montreal Cognitive Assessment (MoCA): Versão final portuguesa [Montreal Cognitive Assessment (MoCA): Final Portuguese version]. Coimbra, Portugal: Serviço de Avaliação Psicológica, Faculdade de Psicologia e de Ciências da Educação o da Universidade de Coimbra; 2008.

13. Alves L, Simões MR, Martins C. The estimation of premorbid intelligence levels among Portuguese speakers: the Irregular Word Reading Test (TeLPI). Arch Clin Neuropsychol. 2012; 27(1):58-68.

14. Brayne C, Beardsall L. Estimation of verbal intelligence in the elderly community: an epidemiological study using NART. $\mathrm{Br}$ J Clin Psychol. 1990;29(pt 2):217-223.

15. Starr JM, Whalley LJ, Inch S, Shering PA. The quantification of the relative effects of age and NART-predicted IQ on cognitive function in healthy old people. Int J Geriatr Psychiatry. 1992; 7(3):153-157.

16. Amieva H, Jacqmin-Gadda H, Orgogozo JM, et al. The 9 year cognitive decline before dementia of the Alzheimer type: a prospective population-based study. Brain. 2005;128(pt 5):1093-1101.

17. Scarmeas N, Albert SM, Manly JJ, Stern Y. Education and rates of cognitive decline in incident Alzheimer's disease. J Neurol Neurosurg Psychiatry. 2006;77(3):308-316.

18. Star JM, Lonie J. Estimated pre-morbid IQ effects on cognitive and functional outcomes in Alzheimer disease: a longitudinal study in a treated cohort. BMC Psychiatry. 2008;8:27.

19. Stern Y. What is cognitive reserve? Theory and research application of the reserve concept. J Int Neuropsychol Soc. 2002;8(3): 448-460.

20. Katzman R. Education and the prevalence of dementia and Alzheimer's disease. Neurology. 1993;43(1):13-20.

21. Satz P. Brain reserve capacity on symptom onset after brain injury: a formulation and review of evidence for the threshold theory. Neuropsychology. 1993;7(3):237-295.

22. Stern Y. Cognitive reserve and Alzheimer disease. Alzheimer Dis Assoc Disord. 2006;20(2):112-117.
23. Rasmusson DX, Carson KA, Brookmeyer R, Kawas C, Brandt J. Predicting rate of cognitive decline in probable Alzheimer's disease. Brain Cogn. 1996;31(2):133-147.

24. Unverzagt FW, Hui SL, Farlow MR, Hall KS, Hendrie HC. Cognitive decline and education in mild dementia. Neurology. 1998;50(1):181-185.

25. Fritsch T, McClendon MJ, Smyth KA, Ogrocki PK. Effects of educational attainment and occupational status on cognitive and functional decline in persons with Alzheimer-type dementia. Int Psychogeriatr. 2002;14(4):347-363.

26. Haxby JV, Raffaele K, Gillette J, Schapiro MB, Rapoport SI. Individual trajectories of cognitive decline in patients with dementia of the Alzheimer's type. J Clin Exp Neuropsychol. 1992;14(4): 575-592.

27. Mortimer JA. Brain reserve and the clinical expression of Alzheimer's disease. Geriatrics. 1977;52(suppl 2):S50-S53.

28. Snowdon DA, Greiner LH, Mortimer JA, Riley KP, Greiner PA, Markesbery WR. Brain infarction and the clinical expression of Alzheimer's disease. The Nun Study. JAMA. 1997;277(10): 813-817.

29. Lindeboom J, Launer LJ, Schmand BA, Hooyer C, Jonker C. Effects of adjustment on the case-finding potential of cognitive tests. J Clin Epidemiol. 1996;49(6):691-695.

30. Alves L, Martins C, Simões MR. Avaliação da Inteligência PréMórbida: Desenvolvimento da versão experimental do Teste de Leitura de Palavras Irregulares (TeLPI) para a População Portuguesa [Premorbid Intelligence Assessment: Experimental version of the Irregular Words Reading Test (TeLPI)]. Psychologica. 2010;52(3):299-312.

31. Alves L, Simões MR, Martins C, Freitas S, Santana I. TeLPI Performance in subjects with mild cognitive impairment and Alzheimer's Disease: a validation study [published online January 14, 2013]. Alzheimer Dis Assoc Disord. 2013.

32. Nelson HE, Wilson J. National Adult Reading Test (NART): Test manual. 2nd ed. London, UK: NFER-Windsor; 1991.

33. Nelson HE. National Adult Reading Test: Test manual. Upton Park, UK: NFER-Windsor; 1982.

34. Wechsler D. Escala de Inteligência de Wechsler para AdultosTerceira edição (WAIS-III) [Wechsler Adult Intelligence Scale. 3rd ed.]. Lisboa, Portugal: Cegoc; 2008.

35. Schretlen DJ, Winicki JM, Meyer SM, Testa SM, Pearlson GD, Gordon B. Development, psychometric properties, and validity of the Hopkins adult reading test (HART). Clin Neuropsychol. 2009;23(6):926-943.

36. NCS Pearson Corporation. Test of Premorbid Functioning-UK version. Oxford, UK: Author; 2011.

37. The Psychological Corporation. Wechsler Test of Adult Reading (WTAR): Test manual. San Antonio, TX: Author; 2001.

38. Rosen WG, Mohs RC, Davis KL. A new rating scale for Alzheimer's Disease. Am J Psychiatry. 1984;141(11):1356-1364.

39. Guerreiro M, Fonseca S, Barreto J, et al. Escala de Avaliação da Demência de Alzheimer [Alzheimer's Disease Assessment Scale]. In: Grupo de Estudos de Envelhecimento Cerebral e Demências, ed. Escalas e testes na demência [Scales and tests in dementia]. Lisboa, Portugal: GEECD; 2008:42-68. 
40. Hughes CP, Berg L, Danzinger WL, Coben LA, Martin RL. A new clinical scale for the staging of dementia. Br J Psychiatry. 1982;140:566-572.

41. Garret C, Santos F, Tracana I, et al. Avaliação Clínica da Demência [Clinical Dementia Rating]. In: Grupo de Estudos de Envelhecimento Cerebral e Demências, ed. Escalas e testes na demência [Scales and tests in dementia]. Lisboa, Portugal: GEECD; 2008: 17-32.

42. Schmand B, Jonker C, Hooijer C, Lindeboom J. Subjective memory complaints may announce dementia. Neurology. 1996;46(1): 121-125.

43. Ginó S, Mendes T, Ribeiro F, et al. Escala de Queixa de Memória [Subjective Memory Complaints Scale]. In: Grupo de Estudos de Envelhecimento Cerebral e Demências, ed. Escalas e testes na demência [Scales and tests in dementia]. Lisboa, Portugal: GEECD; 2008:117-120.

44. Yesavage JA, Brink TL, Rose TL, et al. Development and validation of a geriatric depression screening scale: a preliminary report. Psychiatry Res. 1983;17(1):37-49.

45. Barreto J, Leuschner A, Santos F, et al. Escala de Depressão Geriátrica [Geriatric Depression Screening Scale]. In: Grupo de Estudos de Envelhecimento Cerebral e Demências, ed. Escalas e testes na demência [Scales and tests in dementia]. Lisboa, Portugal: GEECD; 2008:69-72.

46. Petersen RC. Mild cognitive impairment as a diagnostic entity. J Inter Med. 2004;256(3):183-194.

47. American Psychological Association. DSM-IV-TR: Manual de Diagnóstico e Estatística das Perturbações Mentais [DSM-IVTR: Diagnostic and statistical manual of mental disorders] 4th ed. revised text (J.N. Almeida, Trad). Lisboa, Portugal: Climepsi Editores; 2002.

48. McKhann G, Drachman D, Folstein M, Katzman R, Price D, Stadlan EM. Clinical diagnosis of Alzheimer's disease: report of the NINCDS-ADRDA Work Group under the auspices of the
Department of Health and Human Services Task Force on Alzheimer's disease. Neurology. 1984;34(7):939-944.

49. Petersen RC. Mild cognitive impairment. Continuum lifelong learning. Neurology. 2007;13(2):15-38.

50. Freitas S, Simões MR, Alves L, Santana I. Montreal cognitive assessment (MoCA): validation study for mild cognitive impairment and Alzheimer's Disease. Alzheimer Dis Assoc Disord. 2013;27(1):37-43.

51. Cohen J. Statistical Power Analysis for the Behavioural Sciences. 2nd ed. Hillsdale, NJ: Erlbaum; 1988.

52. Del Ser T, González-Montalvo J, Martinez-Espinosa S, DelgadoVillapalos C, Bermejo F. Estimation of premorbid intelligence in Spanish people with the Word Accentuation Test and its application to the diagnosis of dementia. Brain Cogn. 1997;33(3): 343-356.

53. Mackinnon A, Ritchie K, Mulligan R. The measurement properties of a French language adaptation of the National Adult Reading Test. Int J Methods Psychiatr Res. 1999;8(1):27-38.

54. Rolstad S, Nordlund A, Gustavsson MH, et al. The Swedish National Adult Reading Test (NART-SWE): a test of premorbid IQ. Scand J Psychol. 2008;49(6):577-582.

55. Patterson K, Graham N, Hodges JR. Reading in dementia of the Alzheimer type: a preserved ability? Neuropsychology. 1994; 8(3):395-407.

56. Wilson RS, Krueger KR, Boyle PA, Bennett DA. Loss of basic lexical knowledge in old age. J Neurol Neurosurg Psychiatry. 2011;82(4):369-372.

57. Freitas S, Simões MR, Alves L, Santana I. Montreal cognitive assessment (MoCA): normative study for the Portuguese population. J Clin Exp Neuropsychol. 2011;33(9):989-996.

58. O'Carrol DW, Pollit PA, Hyde JB, Fellows JL, Miller ND, Roth M. A follow-up study of dementia diagnosed in the community using the Cambridge Mental Disorders of the Elderly Examination. Acta Psychiatr Scand. 1990;81(1):78-82. 